Belgirate, Italy, 28-30 September 2005

\title{
MECHANISM AND THERMAL EFFECT OF DELAMINATION IN LIGHT-EMITTING DIODE PACKAGES
}

\author{
Jianzheng Hu, Lianqiao Yang, and Moo Whan Shin \\ Department of Materials Science \& Engineering, Myong Ji University, \\ 38-2 Nam-Dong, Yongin-Si, Kyunggi, Korea 449-728 \\ e-mail: mwshin@mju.ac.kr
}

\begin{abstract}
In this paper we report on the mechanism of delamination in light-emitting diode (LED) packages and its effects on thermal characteristics of LEDs. The LED samples were subjected to moisture preconditioning treatments followed by heat block testing. Transient thermal measurements were performed for the investigation of the thermal behavior of the delaminated LEDs. Increase of thermal resistance with the degree of delamination was observed from the transient measurement test. Thermomechanical stress and hygro-mechanical stress in the LED package were obtained by coupled-field analysis using FEA. The calculated thermo-mechanical and hygro-mechanical stress distributions agree well with the micrographical evidence. It was found that the thermomechanical stress plays more important role than the hygro-mechanical stress for the development of delamination in the LED packages. Moisture preconditioning for $3 \mathrm{hrs}$ and $6 \mathrm{hrs}$ under $85^{\circ} \mathrm{C} / 85 \mathrm{RH}$ conditions was found to make little contribution to the delamination between the chip and lead frame. Significant delamination was expected for the samples experienced the moisture preconditioning for $24 \mathrm{hrs}$.
\end{abstract}

\section{INTRODUCTION}

The research efforts on GaN-based light-emitting diodes (LEDs) are kept increasing due to their significant impacts on illumination industry. One of key factors possibly limiting them from such an important application is the life time of LED packages which experience several thermal cycles during the surface mounting process. Delamination is frequently observed in LED packages and directly responsible for mechanical reliability problems and thermal problems for LED packages. So delamination is believed to be critically harmful to the life time of LED package, but there have not been found any theoretical analysis on delamination in LED packages so far. This paper reports on thermal measurement and mechanical analysis of the delamination in GaN-based LED packages.
Surface Mount Technology (SMT) is widely used to mount the LED packages for practical application. In surface mount soldering both the device body and leads are intentionally heated. The heat from soldering causes a buildup of additional stresses within the device that were not present from the manufacturing process. Thermal stress as well as moisture absorbed by the packages is considered to be the main cause for the delamination in electronic package delamination [1]-[2]. The LED packages are molded with polymer plastic materials. The moisture can diffuse into the package. The package will swell after absorbing moisture. The mismatching coefficients of moisture expansion (CMEs) will induce hygro-mechanical stress in the package [3]. The mismatching coefficients of thermal expansion (CTEs) in LED packages induce thermal stress when the package is heated in the reflow soldering process. And the presence of moisture in packages reduces interfacial adhesion strength [4]-[5] and leads to delamination. All these contribute to the delaminations in LED packages. Delaminations are directly responsible for the lateral popcorn failure in reflow soldering process [6]. Delaminations in LED packages block the thermal pass. This is critical for LED thermal performance.

In this work, the delamination in surface mounting LED packages is studied by simulation with hygro-mechanical stress modelling and thermo-mechanical stress modelling. The effect of hygro-mechanical stress and thermomechanical stress on the development of delamination in LED packages is evaluated. Transient thermal measurement was performed for the quantitative comparison of thermal characteristics of samples with different preconditions, which presumably affect the degree of delamination.

\section{EXPERIMENT}

Blue LED packages with the same chip and package structure were divided into 4 groups depending on the degree of pre-conditioning and were labelled as group 1, group 2, group 3, and group 4. Samples of group 1 were as-packaged without any preconditioning and can be 
assumed as free of delamination.. Samples of group 2 through group 4 were preprocessed in two steps. First, samples were subjected to $85^{\circ} \mathrm{C} / 85 \mathrm{RH}$ moisture condition for 3,6 , and 24 hours for group 2, group 3 and group 4 respectively. Secondly, these samples were heated in heat block at $270^{\circ} \mathrm{C}$ for 20 seconds. This moisture preconditioning process refers to a set of standardized procedures to expose an electronic package to such conditions that make it possible to simulate the actual stresses it will experience during shipping and second level mounting [7]. After preprocessing, the macrographs for the lead frame with delamination were obtained from microscope. Thermal transient measurement was done in the following procedures. Transient thermal measurements with Transient Thermal Tester (T3Ster, MicReD Ltd.) were used to investigate the thermal behavior of the delaminated LEDs. T3ster captures the thermal transients real-timely, records the cooling /heating curve and then evaluate the cooling / heating curve to derive the thermal characteristics. Based on the thermal R-C network and structure function theory, the heat path can be determined quantitatively. The first step was to get the $\mathrm{K}$ factor, a constant defining the relationship between the junction temperature change and temperature sensitive parameter (TSP). For compounds LED, TSP is the forward voltage drop of the diode. In the $\mathrm{K}$ factor calibration, $0.5 \mathrm{~mA}$ sensor current in the temperature range of $20{ }^{\circ} \mathrm{C}$ to $50{ }^{\circ} \mathrm{C}$ was used. Transient measurement was started to record the cooling curve after driving the samples with $30 \mathrm{~mA}$ current for 10 minutes at the ambient temperature of $25{ }^{\circ} \mathrm{C}$ to reach the thermal stabilization.

\section{MODELS FOR THE SIMULATION}

\subsection{Thermal Modelling}

The transient heat conduction equation without heat generation shown in Eqn. (1) is used to obtain the temperature distribution during our heat block test.

$\frac{\partial^{2} T}{\partial x^{2}}+\frac{\partial^{2} T}{\partial y^{2}}+\frac{\partial^{2} T}{\partial z^{2}}=\frac{1}{\alpha} \frac{\partial T}{\partial t}$

where the property $\alpha=k / \rho C$ is thermal diffusivity of the material, $k$ is thermal conductivity, $\rho$ is density, and $C$ is specific heat. $T$ is the temperature, $x, y$ and $z$ are the spatial coordinates. For the heat block test, the boundary condition is to apply heat transfer coefficient combining convection and radiation heat transfer to the external surfaces of the LED package. The whole heat transfer coefficient varies with the temperatures of different surfaces of package, and the ambient temperature is fixed

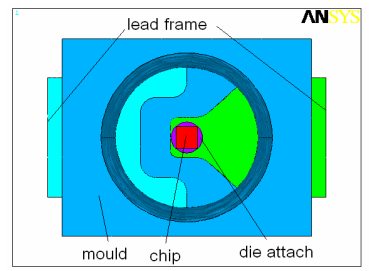

(a)

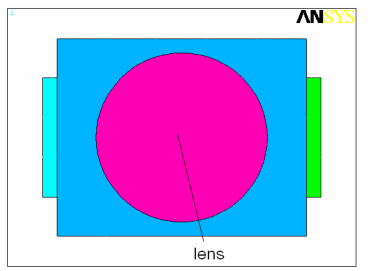

(b)
Fig. 1 Schematic of LED package structure: (a) is internal view; (b) is top view.

at $270{ }^{\circ} \mathrm{C}$. The thermal parameters of LED packaging materials are listed in Table I.

TABLE I

Thermal Property of LED Packaging Materials

\begin{tabular}{cccccc}
\hline \hline Material & SiC & $\begin{array}{c}\text { die } \\
\text { attach }\end{array}$ & $\begin{array}{c}\text { lead } \\
\text { frame }\end{array}$ & mould & $\begin{array}{c}\text { epoxy } \\
\text { lens }\end{array}$ \\
\hline$k\left(\mathrm{~W} / \mathrm{M} \cdot{ }^{\circ} \mathrm{C}\right)$ & 200 & 7.5 & 401 & 0.23 & 0.17 \\
$C\left(\mathrm{~J} / \mathrm{Kg} \cdot{ }^{\circ} \mathrm{C}\right)$ & 1000 & 300 & 385 & 1256 & 1173 \\
$\rho\left(\mathrm{Kg} / \mathrm{m}^{3}\right)$ & 2975 & 2400 & 8300 & 1300 & 980 \\
\hline \hline
\end{tabular}

The modeled structure has a dimension of $3.5 \mathrm{~mm} \times 2.8$ $\mathrm{mm} \times 2.0 \mathrm{~mm}$ and the structure is composed of chip, die attach, lead frame, plastic mould, and epoxy lens as shown in Fig. 1. The investigated LED samples are nonflip chip, so the $\mathrm{SiC}$ substrate is attached to the lead frame by silver epoxy in the model. And the chip is modeled as $\mathrm{SiC}$ for the material properties. Detailed structure of epilayer in the chip was simplified and the effect of gold wire was not considered in modeling. Silver epoxy is used for the die attach. And copper and silver alloy is used for the lead frame, thermal plastic for the mould, and epoxy is used for the lens. All the structural parameters employed in the simulation have the same values as in the real LED package investigated.

\subsection{Thermo-Mechanical Modeling}

As shown in Eqn. (2), thermal stress comes from the expansion of material when heated.

$\sigma=E \alpha\left(T-T_{r e f}\right)$

where the constant, $E$, is elastic modulus. $\alpha, T$, and $T_{r e f}$ is coefficient of thermal expansion (CTE), temperature and reference temperature, respectively. The temperature distribution obtained from the transient thermal analysis for the heat block test is applied as temperature loads for the model. The mechanical properties of materials are temperature dependent, and the mean values for them are listed in Table II. The bottom of LED package is simply supported to limit the rigid displacement. 
TABLE II

Mechanical Property of LED Packaging Materials

\begin{tabular}{cccccc}
\hline Material & $\mathrm{SiC}$ & $\begin{array}{c}\text { Die } \\
\text { Attach }\end{array}$ & $\begin{array}{c}\text { Lead } \\
\text { frame }\end{array}$ & mould & $\begin{array}{c}\text { epoxy } \\
\text { lens }\end{array}$ \\
\hline$\alpha, \mathrm{CTE}\left(10^{-6} / \mathrm{K}\right)$ & 14 & 30 & 18 & 45 & 45 \\
Poison's ratio & 0.31 & 0.35 & 0.34 & 0.35 & 0.49 \\
$E(\mathrm{GPa})$ & 190 & 40 & 190 & 5.2 & 0.5 \\
\hline \hline
\end{tabular}

\subsection{Moisture Diffusion Modeling}

Moisture diffusion modelling is based on the analogy between mass diffusion and heat conduction. Transient heat conduction can be modelled by Eqn. (1). Transient moisture diffusion can be modelled by Fick's law of diffusion as described in Eqn. (3).

$\frac{\partial^{2} C}{\partial x^{2}}+\frac{\partial^{2} C}{\partial y^{2}}+\frac{\partial^{2} C}{\partial z^{2}}=\frac{1}{D} \frac{\partial C}{\partial t}$

where $C$ is moisture concentration, $D$ is the moisture diffusivity of respective material. Most commercial FEA programs are capable of solving heat conduction equation. From the analogy with heat conduction, moisture diffusion can be simulated by FEA. As the moisture concentration is discontinuous across material interface [9] Eqn. (3) can not be used in FEA programs for modelling diffusion in multi-material packages. Moisture wetness fraction, W, defined in Eqn. (4), is proved to be continuous across multi-material interface [9].

$W=\frac{C}{C_{\text {sat }}}, \quad 1 \geq W \geq 0$

where $C_{\text {sat }}$ is the saturated moisture concentration of material. By using wetness fraction Eqn. (3) can be reconstructed as Eqn. (5).

$\frac{\partial^{2} W}{\partial x^{2}}+\frac{\partial^{2} W}{\partial y^{2}}+\frac{\partial^{2} W}{\partial z^{2}}=\frac{1}{D} \frac{\partial W}{\partial t}$

For the modelling of moisture diffusion in LED packages, the initial condition is $W=0$ for the whole package as the package is considered to be dry initially. And the boundary condition is $W=1$, for the external surfaces of LED package as exposed to moisture. The chip and the lead frame were assumed not to absorb any water. Therefore, the diffusivity and saturated moisture concentration for the chip and lead frame were set to zero. The parameters for moisture properties for other materials

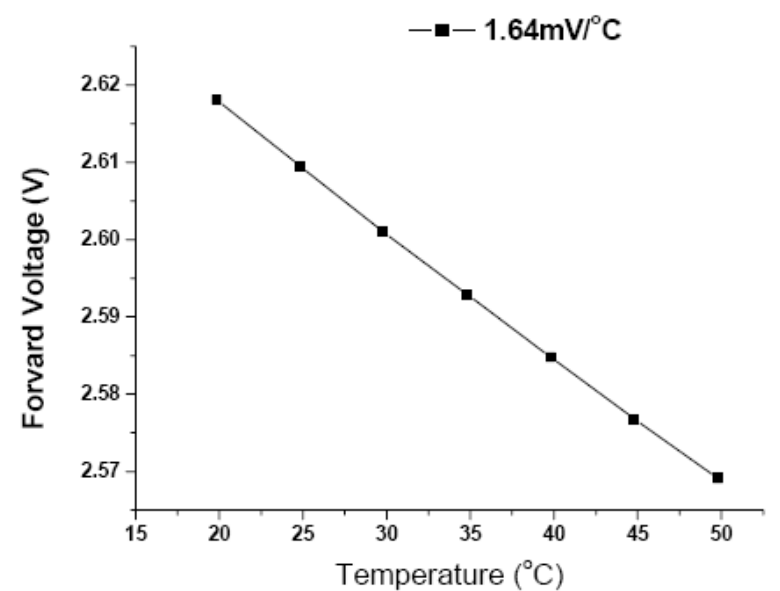

Fig. 2 Forward voltage vs. temperature plot for the calculation of the $K$ factor in LED package.

used in LED package under $85 \mathrm{RH} / 85^{\circ} \mathrm{C}$ moisture condition are listed in Table III.

TABLE III

Moisture Property of LED Packaging Materials

\begin{tabular}{llll}
\hline \hline Material & die attach & mould & epoxy lens \\
\hline$D\left(\mathrm{~m}^{2} / \mathrm{s}\right)$ & $12.5 \mathrm{e}-12$ & $1.886 \mathrm{e}-12$ & $1.886 \mathrm{e}-12$ \\
$C_{\text {sat }}\left(\mathrm{kg} / \mathrm{m}^{2}\right)$ & 6.20 & 4.88 & 4.88 \\
$\beta, \mathrm{CME}\left(\mathrm{m}^{3} / \mathrm{kg}\right)$ & $0.445 \mathrm{e}-3$ & $0.210 \mathrm{e}-3$ & $0.210 \mathrm{e}-3$ \\
\hline \hline
\end{tabular}

\subsection{Hygro-Mechanical Modeling}

The sorption of moisture can induce hygroscopic swelling in the LED packaging materials such as molding polymer, die attachment and epoxy lens. The hygroscopic swelling linearly increases with moisture content [3]. The mismatching coefficient of moisture expansion (CME), $\beta$, will cause hygroscopic swelling stress in the package. This is analogous to the expansion induced by mismatching of CTEs. By substituting $\alpha$ and T in Eqn. (2) with $\beta$ and $C$, respectively we can obtain the hygroscopic stress Eqn. (6). The CME and $C_{\text {sat }}$ used for calculating hygroscopic stress in LED package are listed in Table III.

$$
\sigma=E \beta\left(C-C_{r e f}\right)
$$

\section{RESULTS AND DISCUSSION}

\subsection{Thermal Measurement}

$\mathrm{K}$ factor is calibrated based on Eqn. (7) as shown in Fig.2. The obtained $\mathrm{K}$ factors are $2.69 \mathrm{mV} / \mathrm{K}, 1.67 \mathrm{mV} / \mathrm{K}, 1.62$ $\mathrm{mV} / \mathrm{K}$, and $1.64 \mathrm{mV} / \mathrm{K}$ for group 1 , group 2, group 3, and group 4 , respectively. 


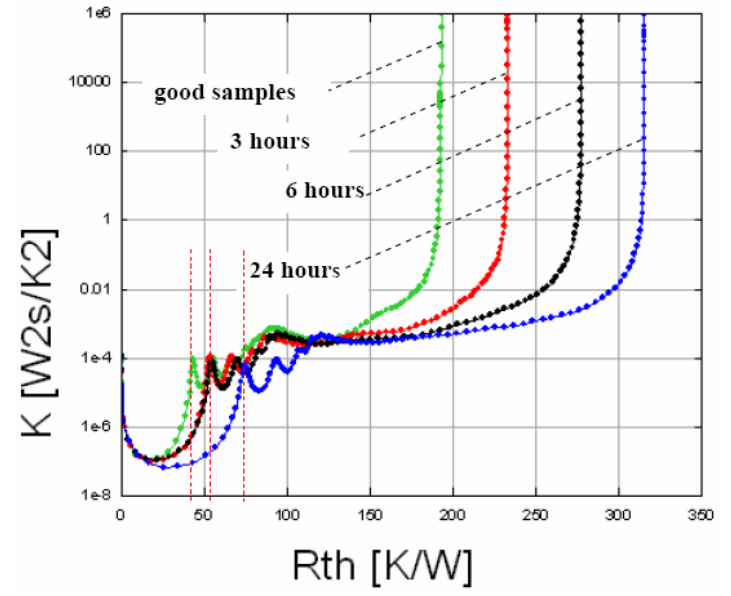

Fig. 3 The differential structure function for the LED packages with different degree of delamination.

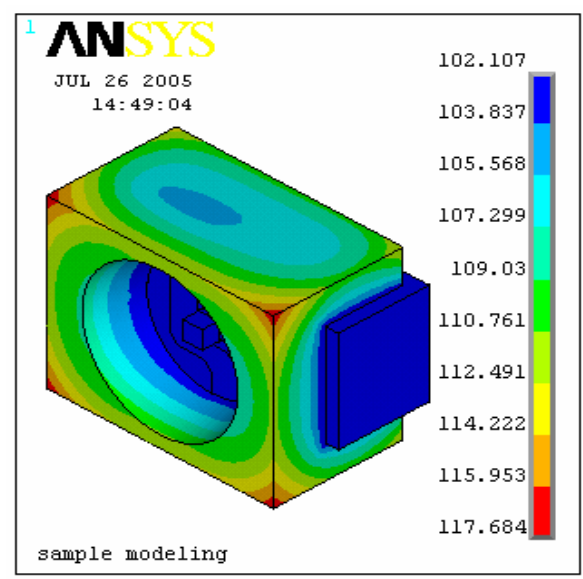

Fig. 4 Temperature distribution of LED packages: the calculation was made by FEA.

$K=\Delta T_{J} / \Delta V_{F}$

where $\Delta T_{J}$ is the change junction temperature of LED, $\triangle V_{F}$ is the change of forward voltage in LED.

The differential structure function [10]-[11] is defined as the derivative of the cumulative thermal capacitance with respect to the cumulative thermal resistance (Eqn. 8). And Eqn. (8) can be further transformed to Eqn. (9).

$$
\begin{aligned}
& K\left(R_{\Sigma}\right)=\frac{d C_{\Sigma}}{d R_{\Sigma}} \\
& K\left(R_{\Sigma}\right)=\frac{c A d x}{d x / \lambda A}=c \lambda A^{2}
\end{aligned}
$$

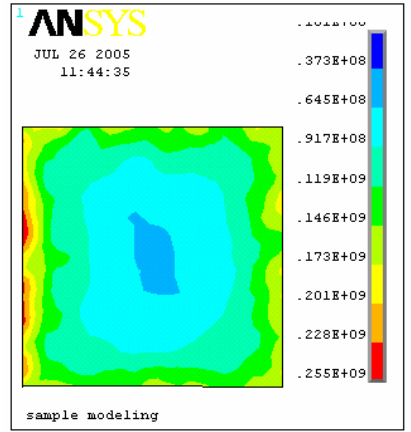

(a)

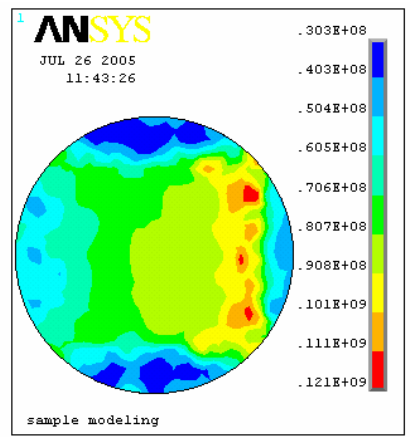

(b)
Fig. 5 Distribution of thermo-mechanical stress in LED package: (a) chip stress, (b) die attach stress.

where $c$ is the volumetric heat capacitance, $\lambda$ is the thermal conductivity, and $A$ is the cross sectional area of the heat flow. So thermal resistance change causing by $c$, $\lambda$ or $A$ can be observed in the plot of differential structure function [12].

The recorded cooling curve in the transient measurement was evaluated in T3Ster to extract the thermal characteristic parameters. We utilized the differential structure function obtained from the evaluation to identify the partial thermal resistance of different sections in the heat conductance path [12]-[13]. From the differential structure functions shown in Fig. 3 we can find that the thermal resistances change with the moisture preconditioning time. Samples with preprocessing for 3 hours and 6 hours have nearly the same value of thermal resistance (about $52.2 \mathrm{~K} / \mathrm{W}$ ) from the chip to lead frame, which corresponds to the initial range in the K vs. R diagram. The pre-conditioning time of $6 \mathrm{hrs}$ is regarded as too short for the moisture to diffuse to the die attach and cause delamination and this can be observed from the lateral diffusion simulation. Samples with preprocessing for 3 hours and 6 hours have smaller thermal resistance from the chip to lead frame than the samples with preprocessing for 24 hours, which thermal resistance from the chip to lead frame is $70.9 \mathrm{~K} / \mathrm{W}$. However, all the samples with preprocessing have larger thermal resistances from chip to lead frame than the unpreprocessed samples presumed to be without delamination, which thermal resistance from the chip to lead frame is $41.7 \mathrm{~K} / \mathrm{W}$. So we can figure out that delamination between the chip and the lead frame is developed as the processing time increases.

\subsection{Thermal and Thermo-Mechanical Simulation}

In the transient thermal analysis it was observed that the temperature of chip increases from initial temperature $25^{\circ} \mathrm{C}$ to about $102^{\circ} \mathrm{C}$ in the 20 seconds heating process. 


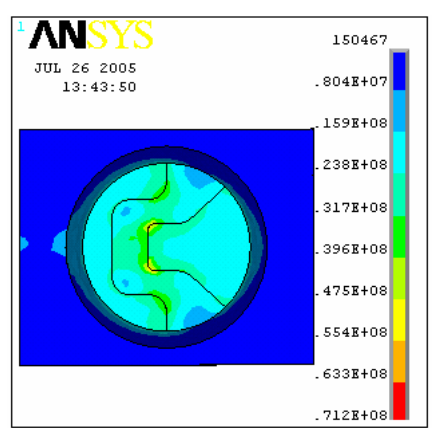

(a)

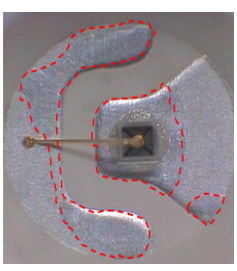

(b)
Fig. 6 Comparison of (a) simulated distribution of thermo-mechanical stress with (b) micrograph of delaminated lead frame.

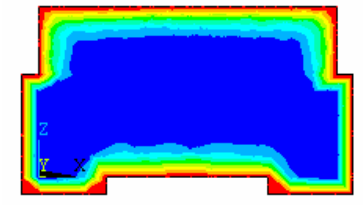

3 hours

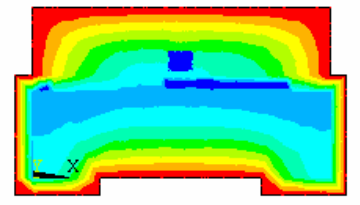

24 hours

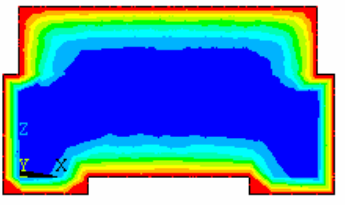

6 hours

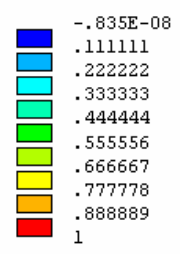

Fig. 7 Distribution of wetness fraction in LED package: the simulation was made by FEA.

High temperature gradient exists in the package as shown in Fig. 4. This high temperature gradient and the mismatching CTEs have induced high thermo-mechanical stress in the package. As shown in Fig. 5 high stress exists at the interface of the chip and die attach. The maximum Von. Mises stress is $255 \mathrm{MPa}$ and $121 \mathrm{MPa}$ for the chip and silver epoxy die attach, respectively. This stress can lead to interface breaking between the chip and die attach.

Lower stress is observed at the interface between the lead frame and mould. The higher stress appears at the outer edge of the lead frame, which agrees well with the observation from the micrographs as shown in Fig. 6.

\subsection{Moisture Diffusion and Hygro-mechanical Stress}

The simulated moisture distribution in the LED package (section view) for the samples with preprocessing for 3 hours, 6 hours and 24 hours is shown in Fig. 7 and Fig. 8 for wetness fraction and moisture concentration, respectively. From the plot we can find that the wetness

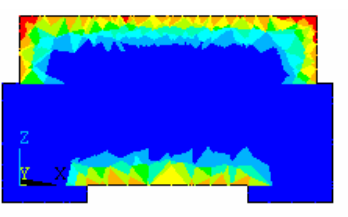

3 hours

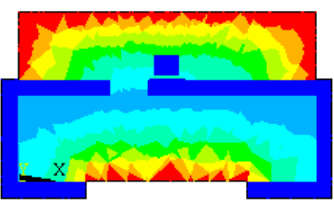

24 hours

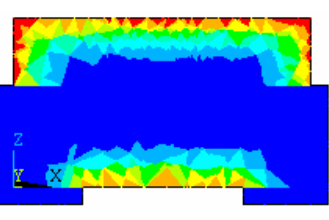

6 hours

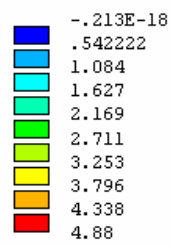

moisture concentration in LED package.

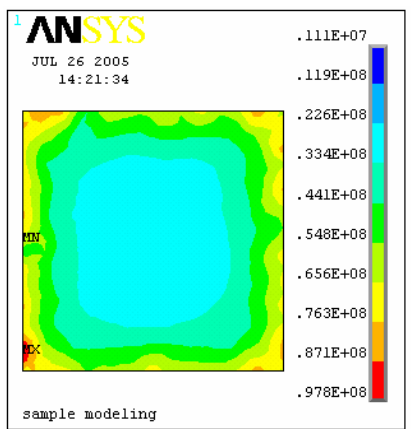

(a)

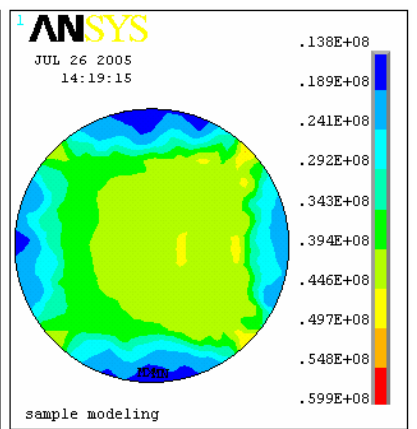

(b)
Fig. 9 Hygroscopic stress for (a) chip (b) die attach.

fraction is continuous in the whole package. However, the moisture concentration is discontinuous. That is why we have to use wetness fraction in FEA modelling. For samples with preprocessing for 3 hours and 6 hours we observe that there is little moisture in the die attach area as the maximum moisture concentration in the die attach is $0.01662 \mathrm{~kg} / \mathrm{m} 3$ and $0.141 \mathrm{~kg} / \mathrm{m} 3$ respectively. So we can figure out that moisture's effect is little for the delaminations between the chip and lead frame for the LED samples with preprocessing for 3 and 6 hours. This agrees with our thermal measurement data: the thermal resistances from chip to lead frame are same for the samples with preprocessing for 3 and 6 hours. However for the samples with preprocessing for 24 hours, the maximum moisture concentration in the die attach is $3.253 \mathrm{~kg} / \mathrm{m} 3$ this cause further delaminations and make the thermal resistance from chip to lead frame is much larger than the samples with moisture preprocessing for 3 and 6 hours.

The simulated hygroscopic stress is shown in Fig. 9 and Fig. 10. The maximum Von Mises stress is $97.8 \mathrm{MPa}$ and 59.9 $\mathrm{MPa}$ for the chip and die attach, respectively. And for the lead frame the higher stress areas, shown in Fig. 10 


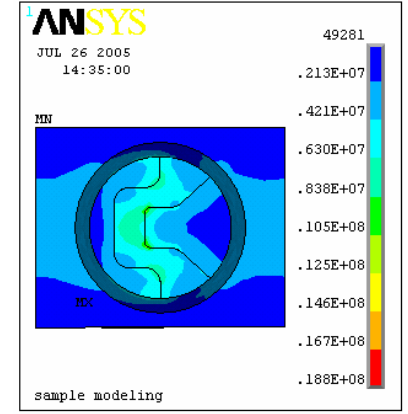

(a)

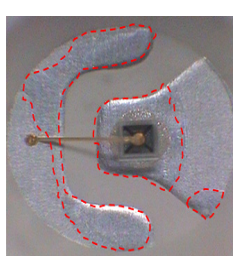

(b)
Fig. 10 Comparison of (a) simulated hygromechanical stress distribution with (b) micrograph of delaminated lead frame.

(a), are nearly same with the stress distribution induced by mismatching CTEs. So the resultant stress caused by mismatching CTEs and CMEs agree with what we observed for the delamination of lead frame, shown in Fig. 10 (b). The maximum hygroscopic Von Mises stress for the whole LED package is $97.8 \mathrm{MPa}$. This stress is much less than the maximum Von Mises stress caused by mismatching CTEs, $255 \mathrm{MPa}$. So for the delaminations in the LED package the thermal mechanical stress induced by mismatching CTEs has the decisive effect.

\section{CONCLUSION}

In this paper, processing parameters were investigated using simulation and experiments for the clear understanding of the delamination mechanism in LED packaging. For the investigated LED samples, $85^{\circ} \mathrm{C} / 85 \mathrm{RH}$ moisture preprocessing for 3 and 6 hours do not show significant effect on the delaminations. $85^{\circ} \mathrm{C} / 85 \mathrm{RH}$ moisture preprocessing for 24 hours causes further delaminations between the chip and lead frame. This was verified by the thermal measurement. The thermo-mechanical stress contributed much more than the hygro-mechanical stress to the delaminations in LED packages. The delaminations between the chip and lead frame have blocked the heat path, and increase the thermal resistance from the chip to lead frame. This will result in much higher junction temperature, which is critically harmful to the life time of LED package.

\section{ACKNOWLEDGEMENT}

This work was supported by grant No. R01-2002-00000356-0 from the Basic Research Program of the Korea Science \& Engineering Foundation. Support from the Korea Institute of Industry Technology Evaluation \& Planning is also appreciated.

\section{REFERENCES}

[1] D. A. Jeannotte, L. S. Goldmann, R T. Howard, "Package Reliability", in Microelectronics Packing Handbook, R. R. Tummula, E. J. Rymaszewski, eds., New York: Van Nostrand Reinhold, 1989.

[2] D. Suhir, "Thermally induced IC package cracking", IEEE trans. Comp., Hybrids, Manufact. Technol., vol. 13, pp.940-945, Dec. 1990.

[3] E. H. Wong, R. Rajoo, S. W. Koh, and T. B. Lim, "The mechanics and impact of hygroscopic swelling of polymeric materials in electronic packaging," ASME JEP, vol. 124, pp. 122-126, 2002.

[4] V. Gektin and A. Bar-Cohen, "Mechanistic figures of merit for die-attach materials," in Proc. ITHERM V, InterSoc. Conf. Therm. Phen. El. Syst., Orlando, FL, 1996, pp. 306-313.

[5] R. Schmidt, P. Alpern, K. Plecher, and R. Tilgner, "Investigation of the adhesion strength between $\mathrm{MC}$ and leadframe at higher temperatures," in Proc. IEEE Electron, Packag. Technol. Conf., 1998, pp.349-353.

[6] Makoto Kitano, Asao Nishimura, and Sueo Kawai, " Analysis of package cracking during reflow soldering process,” IEEE/IRPS, 1988, pp.90-95

[7] "Preconditioning of plastic surface mount devices prior to reliability testing”, JESD22-A113, 1999.

[8] J. Crank, G.S. Park, "The mathematics of diffusion", Oxford university press, 1956.

[9] E. H. Wong, Y. C. Teo, T. B. Lim, "Moisture diffusion and vapour pressure modeling of IC packaging", Proc. 48th ECTC, PP. 1372-1378, 1998

[10] V. Székely and Tran Van Bien, "Fine structure of heat flow path in semiconductor devices: a measurement and identification method", Solid-State Electronics, V.31, pp.13631368 (1988).

[11] V. Székely, "A new evaluation method of thermal transient results", Microelectronics Journal, Vol. 28, No. 3, pp.277-292, 1997

[12] M. Rencz, V. Székely, A. Morelli and C. Villa, "Structure function evaluation of stacked dies", 20th IEEE SEMI-THERM Symposium.

[13] M. Rencz, V. Székely, A. Morelli and C. Villa, "Determining Partial Thermal Resistance with Transient Measurements, and Using the Method to Detect Die Attach Discontinuities", 18th IEEE SEMI-THERM Symposium. 